ISAHP 1996, Vancouvver, Canada, July 12 - 15, 1996

\title{
ACTIVITY-BASED ALLOCATION OF MARKETING OVERHEADS WITH THE AID OF THE ANALYTIC HIERARCHY PROCESS
}

\author{
Gerald Graf \\ Institute of Marketing \\ University of Mannheim, 68133 Mannheim, Germany \\ ggraf@restrum.uni-mannheim.de
}

\begin{abstract}
The measurement of marketing overheads is not an area to which great attention is paid in marketing and accounting literature, even though in practice a large proportion of operating overheads are a result of marketing activities. These costs are difficult to measure because traditional costing systems either fail to provide suitable reference figures for allocating marketing overheads or are designed for other types of calculation (production).
\end{abstract}

The Activity-Based Costing system (ABC), which has recently been the subject of intense discussion, represents the only cost analysis method which is suited to apportioning marketing costs not onily to products, but also to marketing activities and marketing-specific segments. In practice, however, $\mathrm{ABC}$ is extremely problematic to implement and entails high costs for determining and measuring the activities.

This new approach for apportioning marketing overheads is based on a combination of the Analytic Hierarchy Process (AHP) and the German activity-based costing system, which while sharing the essential features of $A B C$ is more sophisticated.

In addition to known, hard data, the activity-based'allocation model for marketing overheads takes account of the subjective judgments of managers in order to-measure the costs entailed by activities with the aid of the AHP. It thus permits a realistic allocation' of prorated overheads to the relevant costing objects. This method is distinguished by the fàct-that little outlay is required for data collection and analyses, making it possible to dispense with such techniques as Zero-Based Budgeting and Overhead Value Analyses, which are normally used to determine and méasure activities. It moreover enables low-cost - and above ali'trelevant information to be made available to the managenent extremely fast.

The most significant advantages of this approach are as follows:

- The AHP allows marketing overheads to be mapped realistically for the very first time

- Costing expenses are low

- The model is sufficientiy flexible to permit sensitivity analyses, which support marketing controlling

- The costs of future activities (e.g. marketing activities accompanying the launch of new products) can be simulated

- The costs of business relations (both internal and external) can be estimated

- The function of marketing as an internal service provider can be mapped in terms of costs, allowing cost rates to be calculated

The presentation covers the German activity-based costing system (Prozesskostenrechnung), the activity-based AHP model and an example of a simulated system. 